\title{
The Relationship between Socio-Demographics and Stress
}

\section{Levels, Stressors, and Coping Mechanisms}

\section{among Undergraduate Students at a University in Barbados}

\author{
Nadini Persaud ${ }^{1} \&$ Indeira Persaud $^{2}$ \\ ${ }^{1}$ Department of Management Studies, Faculty of Social Sciences, University of the West Indies, Cave Hill Campus, \\ St. Michael, Barbados. \\ ${ }^{2}$ Department of Psychology, Division of Arts, Science, and General Studies, St. Vincent and the Grenadines \\ Community College, Villa Campus, St. Vincent. \\ Correspondence: Nadini Persaud, Department of Management Studies, Faculty of Social Sciences, University of the \\ West Indies, Cave Hill Campus, St. Michael, Barbados. Tel: 1-246-417-4295. E-mail: \\ nadini.persaud@cavehill.uwi.edu
}

Received: September 29, 2015

Accepted: October 18, $2015 \quad$ Online Published: October 20, 2015

doi:10.5430/ijhe.v5n1p11

URL: http://dx.doi.org/10.5430/ijhe.v5n1p11

\begin{abstract}
This study sought to learn about stress experienced by students enrolled in the Faculty of Social Sciences (FSS) at the University of the West Indies (UWI) in Barbados. This research was primarily undertaken to help UWI administrators/academic staff understand and address student stress. One hundred and six FSS students responded to:- (1) student perceptions on whether summer school courses were less stressful compared to semester courses, (2) the mean stress level associated with summer and semester courses, (3) FSS student stressors, and (4) coping mechanisms used by FSS students to handle stressors. The research revealed a statistically significant difference in the mean stress levels that students experienced between summer and semester courses. The key stressors identified were: (i) amount of work in each course, (ii) group projects being a nightmare, (iii) studying and working full-time, (iv) stress associated with work impacting studies, and (v) taking too many courses per semester. The primary coping strategies used by FSS students were: (i) taking some quiet time and then resuming studies, (ii) praying for renewed strength, (iii) sleeping more, (iv) eating more, and (v) engaging in a hobby. Statistically significant results were observed on several of the key stressors and coping mechanisms. The paper concludes by discussing implications for policy and practice which can aid UWI administration/academic staff to craft strategies that can assist in reducing the amount of stress experienced by students.
\end{abstract}

Keywords: University of the West Indies, Stress, Stressors, Coping mechanisms, Summer School, Semester

\section{Introduction}

A body of literature exists on university student stress, stressors, and coping mechanisms. Additionally, some research has been conducted on tertiary student experiences with semester and summer courses; however, no clear consensus has emerged to date about better student experiences with either semester or summer courses. Moreover, to the best of the researchers' knowledge, very limited research exists regarding the level of student stress in semester versus summer courses. This study adds to the global body of knowledge on university student stress by providing evidence from a new context - Barbados - a small developing country in the Caribbean region.

Two fundamental considerations underpin our study on stress in the Barbados context. The first pertains to a theoretical contribution in order to bridge the gap in the stress literature on:- (i) the extent of student stress in semester versus summer courses, and (ii) studies from developing countries-especially the Caribbean —on student demographics, stressors and coping mechanisms. The second relates to practitioner and policy aspects. Our research should prove beneficial to two primary stakeholder groups, namely, UWI administrators and academic staff since it will provide information useful for crafting polices to reduce the amount of stress experienced by UWI students.

These two considerations give rise to our 7 research questions (RQ): 
RQ(1): Do FSS undergraduate students perceive that summer school courses are less stressful compared to semester courses?

$\mathrm{RQ}(2): \quad$ Is there a difference in the mean stress levels associated with summer and semester courses for FSS undergraduate students?

$\mathrm{RQ}(3)$ : What is the relationship between student demographics and stress levels associated with summer and semester courses?

$\mathrm{RQ}(4): \quad$ What are the key stressors that affect FSS undergraduate students?

$\mathrm{RQ}(5)$ : What is the relationship between student demographics and the stressors that affect FSS undergraduate students?

$\mathrm{RQ}(6): \quad$ What are the key coping mechanisms that FSS undergraduate students use as buffers against stress?

$\mathrm{RQ}(7): \quad$ What is the relationship between student demographics and the coping mechanisms used?

\section{Understanding the Local Context}

\subsection{Barbados Demographics}

Barbados, an island of approximately 439 square kilometers, is located in the Caribbean. English is the official language of Barbados. The island has a population of approximately 289,680 people that is predominantly Black (92\%). Barbados boasts one of the highest literacy rates (99.6\%) globally (Central Intelligence Agency, 2015). The island has some 100 religious denominations with Christianity as the predominant religion (Barbados.Org, 2015).

\subsection{Background on UWI and Semester Versus Summer School Courses}

Founded in 1948, UWI is a public university which serves the region with three campus locations in Barbados (Cave Hill), Jamaica (Mona), and Trinidad and Tobago (St. Augustine). UWI also has an Open Campus to deliver distance education. As of 2014, UWI had a student composition of approximately 33\% male and 67\% females (The University of the West Indies, 2011) and a student enrolment of 46,440 students.

UWI has two academic semesters (September-December and January-May). Each semester comprises 13 weeks. UWI also has a summer school program which runs for 6 weeks (June-July). During the semester, full-time students are required to take 5 courses and part-time students are required to take 3 courses to maintain their academic enrolment status. In contrast, in summer, students can choose a minimum of 1 course without affecting their academic enrolment status. Summer classes tend to be quite small ( $>15$ but $<75$ students) compared to semester courses ( $\geq 200$ students). UWI students take summer school for three primary reasons: (i) in order to complete their degree faster, (ii) to complete a failed course which may be needed as a pre-requisite for another course, and/or (iii) to improve GPA in order to continue studies at UWI.

\section{Literature Review}

\subsection{Overview of Stress}

The positive and negative aspects of stress can be visualized on a continuum. At its best, stress can be a powerful motivator (Rajasekar, 2013) and useful in order for us to protect ourselves - the 'fight or flight' response (Selye, 1979), meet deadlines, strive towards goals, successfully juggle family life, carve careers, meet other daily demands and pursue higher education (Saleh, 2009). Therefore, stress can help to provide challenge and keeps us from becoming too complacent (Health Advocate, 2009); it allows us to hone our skills and to borrow a colloquialism 'keep us on top of our game'. These positive benefits of stress create what White (2009) refers to as the "optimal performance zone" (p.4). In comparison, poor health, deterioration in behavior and attitudes (Schneiderman, Ironson, \& Siegel, 2005), poor grades (Linn \& Zeppa, 1984) as well as lowered motivation (Agolla \& Ongori, 2009) are all examples of when too much stress results in distress.

A stressor can include environmental, academic, health, financial, psychological or family issues (Rajasekar, 2013). However, stress is relative based on several factors which include personality (Rajasekar, 2013), biological vulnerabilities (Schneiderman et al., 2005), social support (Bland, Melton, Welle, \& Bigham, 2012), and stress relieving activities (Ragsdale, Beehr, Grebner, \& Han, 2011). In essence, it is the response to the stressor that varies among people (Busari, 2012) and which determines whether the stress will prove to be beneficial or not. 


\subsection{Demographic Variables and Stressors}

3.2.1 Gender. Several researchers have noted that females experience greater stress than males (Thawabieh \& Qaisy, 2012), and that there are differences in the types and levels of stress (Sulaiman, Hassan, Sapian, \& Abdullah, 2009). A major female academic stressor is social anxiety (Wade, Jacobsen, \& Forste, 2011), while level of financial support (Thawabieh \& Qaisy, 2012) and conflict (Misra \& Castillo, 2004) are major male stressors. Alternatively, other researchers found that regardless of gender, students had similar stress levels in relation to family-life changes, transition into new academic environments (Dyson \& Renk, 2006), and problems with sleep (Waqas, Khan, Sharif, Khalid, \& Ali, 2015).

3.2.2 Full-time Versus Part-time Enrolment. Research indicates that student enrolment status can affect stress levels. Gudrun, Covarrubias Venegas, Simbrunner, and Janous's (2012) longitudinal study in Austria (2009-2011) found that more part-timers in comparison to full-timers (approximately 75\% vs. 60\%) usually work, and part-timers actually work longer hours compared to full-timers (40 hours vs. 20 hours). Consequently, part-timers experience more stress compared to full-timers when academic demands are added to their existing commitments. Other research indicates that many part-timers may be more mature than full-timers and have work experience and the motivation to succeed (Adshead \& Jamieson, 2007); however, depending on when they enter university, they may be anxious (Jones, 2003) about their ability to (i) cope with the work load, and (ii) compete with younger classmates who transition directly from high school into tertiary education (Callender \& Wilkinson, 2012).

3.2.3 Age. Age and maturity may greatly affect types of student stress (The American College Health Association, 2008). Globally, researchers agree that the transition from high school to tertiary education is quite stressful (Rajasekar, 2013). Wade et al. (2011) found that age and maturity tend to lessen social anxiety - a major stressor for young, incoming university students (Arnett, 2006). Alternatively, more mature students may have different kinds of stressors such as life and work responsibilities (Thawabieh \& Qaisy, 2012), but still be motivated to do well to improve employment opportunities (Adshead \& Jamieson, 2007). Comparatively, Misra and Castillo (2004) found no significant differences between age and academic student stressors.

3.2.4 Grade Point Average (GPA). Researchers have noted a negative relationship between stress and GPA (see Busari, 2012; Struthers et al., 2000; Thawabieh \& Qaisy, 2012). In fact, stress and GPA may be bi-directional — where stress can lead to poor performance, or, a low grade can be a further stressor (Agolla \& Ongori, 2009). Stress also tends to result in sleep loss (Ginsberg, 2006) which can negatively impact GPA. Trockel, Barnes, and Egget (2000) noted that comparative to other students, reduced sleep, late rising, and/or long hours of work were more likely to result in poor academic performance. Similarly, Kelly, Kelly, and Clanton (2001) found that students who had less than five hours of sleep were more likely to have lower GPAs.

\subsection{Condensed Summer Courses Versus Semester Courses}

Existing research on semester/summer courses focus primarily on performance-rather than stress. Therefore, we discuss this general literature and then briefly highlight a few specific studies that incorporate stress.

Summer school courses tend to be more condensed than semester courses in terms of longer hours per week (Reardon, Payan, Miller, \& Alexander, 2008) but with fewer weeks (Davies, 2006). Several studies have examined performance levels of students based on condensed summer versus traditional semester courses. Austin and Gustafson's (2006) study of 11,795 University of Georgia students (2001-2004) found that condensed summer courses actually resulted in better grades for students than semester courses due to greater student/teacher interactions and less time to forget the material. Spurling (2001) refers to the latter factor as intensity of study. Further, students are generally more focused with less absenteeism (Scott, 2003), prefer to take condensed courses (Ho \& Polonsky, 2012), and experience greater satisfaction with this choice (Ferguson \& DeFelice, 2010).

Research also indicates an inverse relationship between large class size and academic performance. Specifically, Bandiera, Larcinese, and Rasul's (2010) panel study with university students in the United Kingdom found that reduced class size in summer may be a partial explanation for better summer school performance where top students in particular performed better in smaller classes ( $<100$ students), and "a one standard deviation increase in class size reduces the likelihood that the student obtains an A-grade by 1.1\%" (p.13). Since students may be more stressed in larger classes (Agolla \& Ongori, 2009), this study infers that smaller class sizes may help to mitigate stress effects.

Comparatively, Howell and Johnson's (1982) research indicate that students in condensed courses experience slightly more stress than those in traditional courses, while Daniel's (2000) review explains that students in condensed courses are stressed by the shorter time period for course completion. Daniel (2000) also highlights the work of (i) Petrowsky (1996) where students were very stressed during a two week summer course and performed poorly in comprehensive 
exams, and (ii) Smith (1988) where students were stressed with the amount of work required within the shorter timeframe.

\subsection{Types of Student Stressors}

3.4.1 Work and Study Stress. Workplace studies highlight that working mothers in particular experience quite a lot of stress when they have to juggle multiple roles (Hibel, Mercado, \& Trumbell, 2012). Work-home conflicts may result (Byron, 2005) which ultimately increase stress (Wilks, 2008). When tertiary studies are added, the impact of stress becomes worse (Agolla \& Ongori, 2009). These stressors may lead to or increase fear of poor grades (Johnson, 2009), fear of and/or actual poor performance on exams (Rajasekar, 2013), and inadequate time management/study hours which may lead to poor performance/failure (Struthers et al., 2000).

3.4.2 Amount of Course-work and Number of Courses. The amount of work in each course including homework/number of assignments and group projects (Britz \& Pappas, 2010) can also contribute to stress encountered by college/university students. For example, project members may be lazy, and/or the number of assignments coupled with other responsibilities may lead to student exhaustion. Numerous stressors according to Yang (2004) can lead to student burnout which in turn results in poorer performance. Students may also be overwhelmed by the number of courses they are expected to take (Nasiri \& Shokrpour, 2012) in order to maintain their full-time/part-time enrolment. This can also lead to poor performance/failure (Johnson, 2009; Rajasekar, 2013).

3.4.3 Group Dynamics. Forsythe (2006) explains that effective group work can result in successful accomplishment of a common goal; however, diversity among group members can cause interpersonal conflict. University lecturers may arbitrarily assign groups to accomplish a task, and/or students themselves may create groups. Either strategy may result in conflict.

Students ... are incredibly resentful of those in the group who do not pull their weight, who do not stay on track, who dominate or bully or distract. There can also be groups where members stay silent - or groups where the same people always speak. None of this feels satisfactory and it causes much resentment. (Burns \& Sinfield, 2008, p. 101)

3.4.4 Financial Issues. Worry about financial issues is a common stressor among college/university students (Rajasekar, 2013), is a major contributor for students choosing part-time - rather than full-time — study (Callender \& Wilkinson, 2012) and is responsible for approximately $40 \%$ of the non-traditional freshmen dropout rate (Advisory Committee on Student Financial Assistance, 2012). Likewise, the 2014 Cooperative Institutional Research Program-CIRP freshman survey (153,015 participants) found that approximately $67 \%$ of the respondents were moderately to seriously worried about their ability to finance their undergraduate education (Eagan, Lozano, Hurtado, $\&$ Case, 2014).

3.4.5 Unpleasant Lecturers and Students. Positive interactions with lecturers (Wilks, 2008) produce a conducive learning environment which can increase student motivation. Comparatively, conflicts with unpleasant lecturers (Awino \& Agolla, 2008) increase student stress. Good social support and team work lessens stress (Wilks, 2008), while unpleasant classmates (Awino \& Agolla, 2008) produce or increase stress. Research also suggests that incoming students who can create good social networks (Thawabieh \& Qaisy, 2012) may also experience less stress (Borsari \& Carey, 2006), while the converse is also true (Jackson \& Finney, 2002).

\subsection{Stress Coping Mechanisms}

3.5.1 Approach and Avoidance Strategies. Dombeck (2015) explains that there are two main stress coping styles: approach (e.g., yelling) and avoidance (e.g., not attending classes). According to Dombeck, yelling at others is not very constructive. More constructive approaches include discussing the problem or taking a short time out to control any anger and then returning to calmly address the issue. Comparatively, Dombeck regards avoidance or denial to be an unhealthy coping strategy. For example, students may stop working on the course, avoid classes (Ludovici, 2012), distract themselves from the stressor (Dombeck, 2015), or pretend that nothing is happening - which can lead to emotional exhaustion (Lemaire \& Wallace, 2010).

Struthers et al. (2000) looked at problem-focused coping (comparable to Dombeck's approach strategy) which provided more motivation to perform academically. They also examined emotion-focused coping (comparable to Dombeck's avoidance approach), which they deemed to be more detrimental to both motivation and subsequent academic performance. Signs/symptoms of emotional-focused coping include eating more and crying (Klinic Community Health Centre, 2010; National Institute of Mental Health, 2003). According to Adam and Epel (2007) persons who eat more as a means of dealing with stress actually use food to activate their physiological reward system; they continue to use this strategy because they begin to feel good. However, health issues such as obesity can 
result and the original stressor remains which maintains the behaviour. Donatelle (2012) highlights the positive de-stressing aspect of crying. Men may have different ways of coping with stress (Misra \& Castillo, 2004). For example, women tend to display their feelings more overtly/openly, and older (rather than younger) men are more likely to cry in front of their loved ones (Fox, 2004). Fox also noted that women are more likely to engage in crying as a stress relief mechanism and noted that crying can be "therapeutic, cathartic, de-toxing, [and] stress-busting" (p.2).

3.5.2 Recovery Activities - quiet time/hobbies. Stress recovery activities are important for holistic well-being. Researchers such as Lemaire and Wallace (2010) note that exercise and quiet time (e.g., personal time to recharge) help to mitigate stress. Hobbies (e.g., dancing/games/gardening/music), and relaxation techniques (e.g., meditation/yoga/deep breathing exercises (see Paul, Elam, \& Verhulst, 2007) can also protect against stress since they act as a means of recovery from stress (Ragsdale et al., 2011). For example "relaxation and mastery experiences being related to serenity and positive activation, respectively, goes beyond what one might predict from everyday experience" (Sonnentag, Binnewies, \& Mojza, 2008, p. 681).

3.5.3 Coping strategies that carry social stigma - drugs/smoking/alcohol. Bottorff, Johnson, Moffat, and Mulvogue (2009) found that students use marijuana for stress relief although "marijuana use was the greatest contributor to negative consequences" (Allen \& Holder, 2013, II 1). Similarly, frequent alcohol consumption to de-stress is linked to mental health issues (Dawson, Grant, Stinson, \& Chou, 2005). There is a lack of consensus about the impact of gender on negative coping strategies. Although, Chen, Won, Ran, and Gilson (2009) found that males are more likely to use negative coping strategies, Dyson and Renk (2006) found that regardless of gender, students use similar negative coping strategies - such as alcohol consumption, albeit males may consume more alcohol (Johnsson \& Berglund, 2006). Students may also misuse sleeping pills (Zafar et al., 2008) or prescription stimulants (Allen \& Holder, 2013) in order to combat day time fatigue and sleepiness (Waqas et al., 2015), in an effort to derive better focus, concentration and well-being (Weyandt et al., 2009).

3.5.4 Social networks. Generally, a good social network buffers stress (MacGeorge, Samter, \& Gillihan, 2005) and is comprised of any type of interpersonal connection which can include face-to-face interactions (e.g., mixers/parties/chats) and online socialization. Good friends can increase resilience and decrease stress encountered at university:- "friend support plays a protective role with resilience amid an environment of academic stress" (Wilks, 2008, p. 106). However, both part-time and full-time students may reduce their social and non-academic activities in order to cope with their studies, which according to Gudrun et al. (2012) is counterproductive since socialization acts as a stress buffer. Notwithstanding, too much socialization can be detrimental (Wade et al., 2011) and can result in distraction, gross mismanagement of time, and increased stress.

3.5.5 Prayer. Qidwai, Tabassum, Hanif, and Khan (2009) note that prayer is a common strategy that persons use to cope with stress and maintain good holistic health. The Caribbean region is a melting pot of religions including Christianity, Hinduism, Islam, and Rastafarianism (Edmonds \& Gonzalez, 2010), with one common thread, namely, a greater being to whom followers pray for help and guidance. Prayer can also help to enhance psychological well-being. For example, researchers found "nontrivial and generally salutary effects of religious involvement, especially the frequency of attendance at religious services, on both distress and well-being" (Ellison, Boardman, Williams, \& Jackson, 2001, p. 236), act as buffers against stress (Fabricatore, Handal, \& Fenzel, 2000).

3.5.6 Sleeping. Anxiety caused by academic stress usually translates into students experiencing sleeping problems (Ahrberg, Dresler, Niedermaier, Steiger, \& Genzel, 2012) in terms of less sleep, insomnia, difficulty falling asleep and difficulty remaining asleep. Certain biological mechanisms have been found to greatly impact sleep, while negative impacts to sleep are exacerbated by stressors:

The HPA axis central catecholamine systems and sympathetic system play an important role in the regulation of the sleep-wake cycle...The set point of the HPA axis is genetically determined but can be modulated and reset to other levels by early or later stressful experiences...Depending on the type of dysregulation and the individual's genetic factors or earlier experience, vulnerability may develop to different sleep or mood disorders. (Van Reeth, Weibel, Spiegel, Leproult, Dugovic, \& Maccari, 2000, p. 214-215)

Consequences of chronic sleep disturbances relate to the development and maintenance of psychopathologies and neuro-developmental disorders (Picchioni, Reith, Nadel, \& Smith, 2014). Although anxiety has been widely associated with poor sleep patterns, Sadeh and Gruber (2002) attempted to examine if individuals sleep more as a coping mechanism but found no significant results to support this hypothesis. Alternatively, a better sleep cycle can 
positively affect overall health since it can provide restorative functions to the mind and body (see Picchioni et al., 2014) and facilitate a more positive mood and outlook (Sonnentag et al., 2008).

\subsection{The Present Study}

Given our review, it is important to investigate how the aforementioned issues (semester versus summer stress, types of stressors, and stress coping mechanisms) affect our UWI FSS students compared to the findings highlighted in the literature in order to further the discussion on similarities and differences along with possible explanations. Such knowledge can then inform policy in terms of how UWI can address the issue of stress among its student population.

\section{Methodology}

\subsection{Sample}

The sample comprised 124 randomly selected summer school undergraduate students enrolled in the FSS, UWI, Cave Hill Campus. This represented approximately $10 \%$ of the summer school enrolment for 2014. The response rate was $86 \%(\mathrm{n}=106)$. This sample size — although quite small—met the minimum sample size requirements for the statistical tests conducted (see Harrison \& Brady, 2004). The sample comprised 73 females and 31 males (Missing =2), in keeping with the UWI student enrolment gender ratio. Summer school students were selected since they would have experienced at least a full academic year of studies, thus enabling them to make a comparison between semester and summer stress.

\subsection{Survey Instrument}

4.2.1 Survey Demographics. A self-administered survey (Lavrakas, 2008) was used to collect the data. Section 1 focused on the demographic characteristics of the respondents, namely, gender (male, female), age $(<25,26-35$, 36-45, >45), enrolment-status (full-time, full-time), and GPA. The GPA category which was opened-ended was subsequently recoded into the four categories used by the UWI for the award of a degree, namely, First Class (FC) - GPA $\geq 3.60$, Upper Second (US) - GPA 3.00-3.59, Lower Second (LS) - GPA 2.50-2.99, Pass-2.00-2.49, and the category used by UWI to indicate failure (Fail- GPA 0.00-1.99).

4.2.2 Survey Questions. Section 2 comprised 6 questions (5 closed-ended and 1 open-ended). Question 1 sought to gain insight into stress associated with summer school versus semester courses and used a nominal measurement with Yes/No responses. Question 2 was opened-ended and asked students to provide a reason for their response in Question 1. Questions 3 and 4 sought to ascertain the levels of stress associated with semester versus summer school courses respectively. These two questions used a 10-point interval scale ranging from 1 (Low) to 10 (High). Question 5 dealt with stressors and was classified into 10 categories: (a) Studying and working full-time, (b) Cannot spend much time with my family, (c) Taking too many courses per semester, (d) Amount of work in each course, (e) Group projects are a nightmare, (f) Financial issues associated with funding my studies, (g) Unpleasant lecturers, (h) Unpleasant students, (i) Stress associated with work impacts my studies, and (j) Other (please specify). The final question dealt with potential coping strategies for handling stress. This question included 16 categories: (a) I do nothing, (b) I engage in a hobby (dancing, singing, art etcetera), (c) I get very irritated and yell at others (d) I get irritated with my lecturers, (e) I cry, (f) I stop working on the course, (g) I avoid the lectures and tutorials, (h) I drink alcohol, (i) I take drugs, (j) I smoke, (k) I party/socialize with my friends, (l) I pray for renewed strength, (m) I sleep more, (n) I eat more, (o) I take some quiet time and then resume studies, and (p) Other (please specify). Both questions 5 and 6 allowed students to select multiple categories.

4.2.3 Reliability and Validity of Instrument. A literature review was conducted to identify the types of stressors and coping mechanisms used by other researchers in similar studies prior to survey development. The instrument was then developed; face and content validity of the draft instrument was ascertained by asking colleagues to review/comment on the instrument based on our research questions. Reliability of the instrument was established by conducting a pilot test with 15 similar respondents to check for poorly worded questions and/or imprecise instructions. Analysis of the pilot test surveys using the guidelines provided by Pallant (2003) revealed no problems with reliability.

\subsection{Data Analysis}

The quantitative data was analyzed using descriptive statistics, parametric, and non-parametric tests. Before analyzing the output in each statistical test, checks were made to ensure that the assumptions pertinent to the test in question were not violated using the guidelines provided by Pallant (2003). Thematic analysis was used to analyze the qualitative data. 


\section{Results}

\subsection{Sample Demographics}

The sample comprised 69\% females and 29\% males. Forty-three percent of the students were full-time (Full-time $\mathrm{n}=46$, Part-time $\mathrm{n}=58$, Missing $\mathrm{n}=2$ ). Approximately $74 \%$ of the students who reported age were under the age of $35(<25 \mathrm{n}=32,26-35 \mathrm{n}=14,36-45 \mathrm{n}=9,>45 \mathrm{n}=7)$. Seventy-two percent of students reported their GPA. The mean GPA was 2.82 with a standard deviation of 1.09 ( $F C n=6$, US $n=21$, LS $n=20, \quad$ Pass $n=20$, Fail $n=9$ ).

5.2 Stress Associated with Condensed Summer School Courses Versus Semester Courses-Research Questions (1), (2), and (3)

RQ1. Our first research question elicited responses on whether students perceived that summer school courses were less stressful compared to semester courses. According to our descriptive statistics on Question 1 outlined in Table 1, a higher percentage of students expressed that semester courses were more stressful compared to summer school courses (62\% vs. $38 \%$ ). Thematic analysis of the qualitative responses to the follow-up question (Question 2) which asked students to provide a reason for their response in Question 1 indicated that the three most common reasons expressed by students for less summer school stress were: (i) smaller class numbers which results in more individual attention from lecturer (20\%), (ii) more time to focus on summer course since fewer courses are being taken (15\%), and (iii) easier summer courses compared to semester courses (11\%). In contrast, the most common reason expressed for higher summer stress pertained to the shorter time period in summer which makes it more difficult to absorb material (39\%). Table 1 highlights some of the verbatim responses provided by students on Question 2.

RQ2. To ascertain the mean stress level associated with summer and semester courses, students were asked to rank on a Likert-Scale (Low 1 - High 10), stress associated with a summer course (Question 3) and stress associated with a semester course (Question 4). Table 2 shows the descriptive statistics for RQ2. According to our paired-samples t-test, a statistically significant result was observed between semester stress $(\underline{M}=7.66, \underline{S D}=1.79)$ and summer stress $[(\underline{\mathrm{M}}=6.32, \underline{\mathrm{SD}}=2.55), \mathrm{t}(103)=4.98, \underline{\mathrm{p}}<.01]$. The eta-square statistic $(.19)$ indicated a large effect size. This confirms the previous findings on RQ1.

Table 1. Are Summer Courses Less Stressful than Semester Courses?

\begin{tabular}{llll}
\hline Question & Gender & Response & $\%$ \\
\hline $\begin{array}{l}\text { Q1. Do you find Summer School courses less stressful compared } \\
\text { to Semester courses? }\end{array}$ & Female & Yes & 47 \\
& & No & 26 \\
& Male & Yes & 17 \\
& & No & 14 \\
\hline
\end{tabular}

Q2. Please provide a reason for your answer in Question (1) above.

Summer courses are less stressful compared to semester courses.

- Summer course classes are smaller and more individualized so it is better to understand and ask questions more freely.

- Classes are smaller therefore a lot more is obtained and in many cases greater attention to detail by both lecturer and student. Pressure is minimized significantly.

- Because the work load is less hectic, less course work, you gain more attention because the class size is smaller.

- In the summer you may do two courses at most, so you have more time to focus and apply yourself to the course.

- Summer school tends to be easier.

Summer courses are more stressful compared to semester courses.

- Summer courses are crash courses which makes your life more stressful having to cram 13 weeks of lectures into 6 weeks.

- The time is shorter with longer hours per session leading to more stress in completing assignments.... pressure to learn everything in those six weeks is high. 
RQ3. Our third investigation examined the relationship between demographic factors and stress levels associated with summer and semester courses. On this investigation we observed only two statistically significant results which are shown in Table 2. First, our independent samples t-test which examined the relationship between enrolment-status and summer school stress levels indicated that part-time students experienced higher levels of stress with summer courses compared to full-time students $[(\underline{\mathrm{M}}=6.79, \underline{\mathrm{SD}}=2.41 \mathrm{vs} . \underline{\mathrm{M}}=5.72, \underline{\mathrm{SD}}=2.62), \mathrm{t}(102)=2.17$, $\mathrm{p}=.03$ ]. The magnitude in the means was however quite small (eta-squared $=.04$ ). Second, our ANOVA test which examined the relationship between GPA and summer school stress levels indicated that the mean stress level for the Fail GPA group was significantly higher compared to the mean stress level for the LS GPA group [ $(\mathrm{M}=8.00$, SD 2.24 vs. $\mathrm{M}=5.10, \mathrm{SD} 2.73), \mathrm{F}(4,71)=2.91, \mathrm{p}=.03$ ]. The actual difference in the mean scores between the two groups was quite large (eta-squared $=.15$ ).

\subsection{Stressors for UWI Students—Research Questions (4) and (5)}

RQ4. Question 5 sought to ascertain the key stressors that affect FSS undergraduate students. According to our descriptive statistics shown in Table 3, the five primary stressors identified by our sample of FSS students were:- (i) amount of work in each course (80\%), (ii) group projects being a nightmare (75\%), (iii) studying and working full-time (62\%), (iv) stress associated with work impacting studies (44\%), and (v) taking too many courses per semester (43\%).

RQ5. Our fifth investigation examined the relationship between student demographics and stressors. On this issue we observed eight statistically significant results on our Chi-Square tests. According to Table 3, these results were observed on the demographic variables enrolment-status, age, and GPA.

Enrolment-status. According to our data, full-time students experienced more stress:- (i) with the amount of work in each course ( $\mathrm{FT}=98 \%, \mathrm{PT}=67 \%)$, and (ii) the number of courses taken in the semester $(\mathrm{FT}=53 \%, \mathrm{PT}=35 \%)$. In contrast, part-time students experienced more stress with:- (i) studying and work full-time $(\mathrm{FT}=41 \%, \mathrm{PT}=78 \%)$ and (ii) with work impacting their studies ( $\mathrm{FT}=26 \%, \mathrm{PT}=58 \%$ ).

Table 2. Stress Associated With Summer and Semester Courses

\begin{tabular}{|c|c|c|c|c|c|}
\hline Question & $\mathrm{n}$ & Mean & $\begin{array}{l}\text { Standard } \\
\text { Deviation }\end{array}$ & Mode & $\begin{array}{l}\% \text { of Responses }>5 \\
\text { (Low } 1 \text { - High 10) }\end{array}$ \\
\hline $\begin{array}{l}\text { Q3: Stress associated with Summer } \\
\text { courses. }\end{array}$ & 106 & 6.32 & 2.55 & 10 & 55 \\
\hline $\begin{array}{l}\text { Q4: Stress associated with Semester } \\
\text { courses. }\end{array}$ & 106 & 7.66 & 1.79 & 8 & 88 \\
\hline Demographics & \multicolumn{2}{|c|}{ Groups } & \multicolumn{2}{|c|}{ Summer Mean } & Semester Mean \\
\hline \multirow[t]{2}{*}{ Gender } & \multicolumn{2}{|c|}{ Male } & \multicolumn{2}{|c|}{5.87} & 7.29 \\
\hline & \multicolumn{2}{|c|}{ Female } & \multicolumn{2}{|c|}{6.51} & 7.82 \\
\hline \multirow[t]{2}{*}{ Enrolment-Status } & \multicolumn{2}{|c|}{ Full-Time } & \multicolumn{2}{|c|}{$5.72 *$} & 7.59 \\
\hline & \multicolumn{2}{|c|}{ Part-Time } & \multicolumn{2}{|c|}{$6.79 *$} & 7.72 \\
\hline \multirow[t]{4}{*}{ Age } & \multicolumn{2}{|c|}{$<25$ years } & \multicolumn{2}{|c|}{6.05} & 7.70 \\
\hline & \multicolumn{2}{|c|}{ 26-35 years } & \multicolumn{2}{|c|}{6.55} & 7.95 \\
\hline & \multicolumn{2}{|c|}{$36-45$ years } & \multicolumn{2}{|c|}{6.93} & 7.64 \\
\hline & \multicolumn{2}{|c|}{$>45$ years } & \multicolumn{2}{|c|}{6.64} & 6.91 \\
\hline \multirow[t]{5}{*}{ GPA } & \multicolumn{2}{|l|}{$\mathrm{FC}$} & \multicolumn{2}{|c|}{8.50} & 6.00 \\
\hline & \multicolumn{2}{|l|}{ US } & \multicolumn{2}{|c|}{6.05} & 7.86 \\
\hline & \multicolumn{2}{|l|}{ LS } & \multicolumn{2}{|c|}{$5.10 *$} & 7.30 \\
\hline & \multicolumn{2}{|l|}{ Pass } & \multicolumn{2}{|c|}{6.45} & 7.50 \\
\hline & \multicolumn{2}{|l|}{ Fail } & \multicolumn{2}{|c|}{$8.00 *$} & 7.56 \\
\hline
\end{tabular}

*Statistically significant at $\mathrm{p}<.05$ 
Age. On this demographic, younger students experienced more stress in coping with the amount of work in each course $(<25=93 \%, 26-36=82 \%, 36-45=56 \%,>45=55 \%)$, while older students experienced more stress:- (i) with studying and working full-time $(<25=41 \%, 26-36=68 \%, 36-45=100 \%,>45=100 \%)$, and (ii) with work impacting their studies $(<25=30 \%, 26-36=36 \%, 36-45=75 \%,>45=82 \%)$.

GPA. Our final demographic GPA revealed that a higher percentage of students in the Fail GPA group and the FC GPA group expressed that unpleasant students was a stressor (Fail $=78 \%$, Pass $=55 \%, \mathrm{LS}=25 \%$, US $=33 \%$, $\mathrm{FC}=100 \%)$.

\subsection{Stress Coping Mechanisms-Research Questions (6) and (7)}

RQ6. To ascertain which coping mechanisms FSS students used to deal with the stress, students were asked the question "What are some of the things you do when stressed about your studies at UWI"? Students were provided with the 16 categories shown in Table 4 and were instructed to select all that applied. Analysis of the descriptive statistics indicate that the five top strategies used by FSS students to cope with stress were:- (i) taking some quiet time and then resuming work (72\%), (ii) praying for renewed strength (56\%), (iii) sleeping more (41\%), (iv) eating more (37\%), and (v) engaging in a hobby (32\%).

Table 3. Stressors for UWI Students

\begin{tabular}{|c|c|c|c|c|c|}
\hline \multicolumn{2}{|l|}{ Question } & \multirow{2}{*}{$\begin{array}{c}\mathrm{n} \\
106 \\
\end{array}$} & \multirow{2}{*}{$\begin{array}{c}\text { Total } \\
\% \\
\end{array}$} & \multirow{2}{*}{$\begin{array}{c}\text { Male } \\
\%\end{array}$} & \multirow{2}{*}{$\begin{array}{c}\text { Female } \\
\%\end{array}$} \\
\hline & & & & & \\
\hline \multicolumn{6}{|c|}{ Q5: What are some of the issues that cause you stress? } \\
\hline \multicolumn{6}{|c|}{ Please tick all that apply: } \\
\hline \multicolumn{2}{|c|}{ - Amount of work in each course } & 85 & 80 & 74 & 83 \\
\hline \multicolumn{2}{|c|}{ - Group projects are a nightmare } & 80 & 75 & 64 & 80 \\
\hline \multicolumn{2}{|c|}{ - Studying and working full-time } & 66 & 62 & 65 & 61 \\
\hline \multicolumn{2}{|c|}{ - Stress associated with work impacts my studies } & 47 & 44 & 42 & 45 \\
\hline \multicolumn{2}{|c|}{ - Taking too many courses per semester } & 46 & 43 & 42 & 44 \\
\hline \multicolumn{2}{|c|}{ - Unpleasant lecturers } & 45 & 42 & 29 & 48 \\
\hline \multicolumn{2}{|c|}{ - Unpleasant students } & 39 & 37 & 29 & 40 \\
\hline \multicolumn{2}{|c|}{ - Cannot spend much time with my family } & 33 & 31 & 23 & 35 \\
\hline \multicolumn{2}{|c|}{ - Financial issues associated with funding my studies } & 21 & 20 & 13 & 23 \\
\hline \multicolumn{2}{|c|}{ - Other, please specify } & 6 & 6 & 6 & 6 \\
\hline \multicolumn{2}{|r|}{ Crosstabs $^{1,2}$} & df & $\mathrm{n}$ & value & $\mathrm{p}$ \\
\hline \multirow[t]{4}{*}{ Enrolment Status } & Amount of work in each course & 1 & 106 & 15.91 & $<.001 *$ \\
\hline & Studying and working full-time & 1 & 106 & 15.20 & $<.001 *$ \\
\hline & Stress associated with work impacts my studies & 1 & 106 & 10.97 & $.001 *$ \\
\hline & Taking too many courses per semester & 1 & 106 & 3.97 & $.046^{*}$ \\
\hline \multirow[t]{3}{*}{ Age } & Amount of work in each course & 3 & 105 & 16.46 & $.001 *$ \\
\hline & Studying and working full-time & 3 & 105 & 27.29 & $<.001 *$ \\
\hline & Stress associated with work impacts my studies & 3 & 105 & 17.39 & $<.001 *$ \\
\hline GPA & Unpleasant students & 4 & 72 & 11.01 & $.012 *$ \\
\hline
\end{tabular}

\footnotetext{
${ }^{1}$ Pearson Chi-Square tests were conducted between gender, enrolment-status, age, and GPA on all the issues in Q5.

${ }^{2}$ Only statistically significant results are reported in this table.

$*$ Statistically significant at $\mathrm{p}<.001$ and $\mathrm{p}<.05$
} 
RQ7. Our final investigation examined the relationship between student demographics and the coping mechanisms used by our sample of FSS students. Eight statistically significant results were observed on our Chi-Square tests, namely on the demographic variables gender, enrolment-status, and age. These results are shown in Table 4.

Gender. Females ate more when stressed $(\mathrm{M}=23 \%, \mathrm{~F}=43 \%)$, and a higher percentage of males smoked $(\mathrm{M}=10 \%$, $\mathrm{F}=1 \%)$ or used drugs $(\mathrm{M}=7 \%, \mathrm{~F}=0 \%)$ to cope with stress.

Table 4. Coping Mechanisms For Dealing With Stress

\begin{tabular}{|c|c|c|c|c|c|}
\hline \multicolumn{2}{|l|}{ Question } & $\mathrm{n}$ & Total & Male & Female \\
\hline \multirow{2}{*}{\multicolumn{6}{|c|}{$\begin{array}{l}\text { Q6: What are some of the things you do when stressed about your studies } \\
\text { at UWI? Please tick all that apply. }\end{array}$}} \\
\hline & & & & & \\
\hline \multicolumn{2}{|c|}{ - Take some quiet time and then resume studies } & 76 & 72 & 61 & 76 \\
\hline \multicolumn{2}{|c|}{ - Pray for renewed strength } & 59 & 56 & 48 & 59 \\
\hline \multicolumn{2}{|l|}{ - Sleep more } & 43 & 41 & 36 & 43 \\
\hline \multicolumn{2}{|l|}{ - Eat more } & 39 & 37 & 23 & 43 \\
\hline \multicolumn{2}{|c|}{ - Engage in a hobby (dancing, singing, art etc.) } & 34 & 32 & 45 & 27 \\
\hline \multicolumn{2}{|c|}{ - Party/socialize with friends } & 23 & 22 & 16 & 24 \\
\hline \multicolumn{2}{|l|}{ - Nothing } & 18 & 17 & 10 & 20 \\
\hline \multicolumn{2}{|c|}{ - Get irritable and yell at others } & 17 & 16 & 23 & 13 \\
\hline \multicolumn{2}{|l|}{ - Cry } & 16 & 15 & 7 & 19 \\
\hline \multicolumn{2}{|c|}{ - Stop working on the course } & 12 & 11 & 16 & 9 \\
\hline \multicolumn{2}{|c|}{ - Avoid lectures and tutorials } & 12 & 11 & 13 & 11 \\
\hline \multicolumn{2}{|c|}{ - Drink alcohol } & 11 & 10 & 16 & 8 \\
\hline \multicolumn{2}{|c|}{ - Get irritated with my lecturers } & 10 & 9 & 7 & 11 \\
\hline \multicolumn{2}{|c|}{ - Other, please specify } & 7 & 7 & 13 & 4 \\
\hline \multicolumn{2}{|l|}{ - Smoke } & 4 & 4 & 10 & 1 \\
\hline \multicolumn{2}{|l|}{ - Take drugs } & 2 & 2 & 7 & 0 \\
\hline & Crosstabs $^{1,2}$ & $\mathrm{df}$ & $\mathrm{n}$ & value & $\mathrm{p}$ \\
\hline \multirow[t]{3}{*}{ Gender } & Eat more & 1 & 106 & 3.81 & $.051 *$ \\
\hline & Smoke & 1 & 106 & 4.21 & $.040 *$ \\
\hline & Take drugs & 1 & 106 & 4.93 & $.026^{*}$ \\
\hline \multirow[t]{3}{*}{ Enrolment Status } & Eat more & 1 & 106 & 4.01 & $.045^{*}$ \\
\hline & Engage in a hobby & 1 & 106 & 9.25 & $.002 *$ \\
\hline & Party/socialize with friends & 1 & 106 & 5.69 & $.017 *$ \\
\hline \multirow[t]{2}{*}{ Age } & Sleep more & 3 & 105 & 9.54 & $.023 *$ \\
\hline & Party/socialize with friends & 3 & 105 & 11.01 & $.012 *$ \\
\hline
\end{tabular}

$1 \longdiv { \text { Pearson Chi-Square tests were conducted between gender, enrolment status, age, and GPA on all the issues in Q6. } }$

${ }^{2}$ Only statistically significant results are reported in this table.

* Statistically significant at $\mathrm{p} \leq .05$

Enrolment-status. Part-time students tended to eat more as a coping strategy $(\mathrm{FT}=26 \%$, PT $=45 \%$ ), and more full-time students relieved stress by:- (i) engaging in a hobby (FT $=48 \%, \mathrm{PT}=20 \%$ ) and (ii) using the party/socialize with friends strategy to relieve stress $(\mathrm{FT}=33 \%, \mathrm{PT}=13)$. 
Age. Students under age 25 tended to: (i) sleep more ( $<25=54 \%, 26-36=27 \%, 36-45=19 \%,>45=27 \%)$, and (ii) party/socialise with friends more as coping mechanisms $(<25=32 \%, 26-36=23 \%, 36-45=0 \%,>45=0 \%)$.

\section{Discussion}

\subsection{Stress Associated with Condensed Summer School Courses Versus Semester Courses}

According to our descriptive statistics, our findings lend support to the existing literature that summer school courses are less stressful at least as it relates to our sample of FSS UWI students. Our thematic analysis highlighted that FSS students experienced less stress in the summer as a result of smaller class numbers and more individual attention from the lecturer. This supports previous research that less stress is experienced in smaller groups (Bandiera et al., 2010) and that students experience higher overall student satisfaction with smaller classes (Ferguson \& DeFelice, 2010; Scott, 2003). Additionally, our finding of more focus in summer due to fewer courses being taken concurs with research that increased course load leads to greater student stress (see Nasiri \& Shokrpour, 2012; Yang, 2004) which implies that less course load is more manageable and therefore less stressful.

In keeping with RQ1 results, we found that students experienced higher stress levels in the semester. These findings, similar to that of Austin and Gustafson (2006), infer that summer-rather than semester experiences-are less stressful. We offer several possible explanations for the higher semester stress levels experienced by FSS students. First, students take more courses in the semester which can result in more student stress (Nasiri \& Shokrpour, 2012). Second, semester courses carry more group projects, which Burns and Sinfield (2008) contend can result in serious conflicts. These factors influence student focus (Scott, 2003). Finally, UWI semester courses always carry much larger class numbers which can result in more stress (see Agolla \& Ongori, 2009; Bandiera, et al., 2010), and arguably less effective student-teacher interactions (Austin \& Gustafason, 2006).

We also found that part-timers experienced higher stress levels in summer courses compared to full-timers. One possible explanation in keeping with the research of Gudrun et al. (2012) is that UWI part-timers are also usually employed full-time which can increase stress. Additionally, some part-timers impractically undertake the same course load in both summer/semester (2-3 courses). Timetable clashes may also frequently arise because of the shorter duration which means that some students inevitably miss important information. Finally, six credit hours per week per course in summer versus 3 during the semester may also add to the higher stress levels experienced by the part-timers in the summer. However, these explanations require further investigation since the literature did not differentiate between stress and part-timers/full-timers.

Finally, we found that the mean stress level in Summer for the Fail GPA group was significantly higher compared to the mean stress level for the LS GPA group. A probable explanation is that students who carry a Fail GPA enrol in summer school to improve their GPA; however, they may be exceedingly stressed due to fear about their academic future. These findings are consistent with the literature which indicates that students carrying lower GPAs generally experience more stress (see Busari, 2012; Struthers et al., 2000; Thawabieh \& Qaisy, 2012).

\subsection{Stressors for UWI Students}

The primary stressors reported by our sample are consistent with other studies (see Agolla \& Ongori, 2009; McKenzie \& Schweitzer, 2001; Rajasekar, 2013) which note that volume of work in courses, including number of assignments and group projects (Britz \& Pappas, 2010), along with number of courses taken (see Nasiri \& Shokrpour, 2012) all contribute to stress experienced by college/university students. Additionally, when students have other commitments such as full-time jobs and family commitments, stress can increase with added academic pursuits (Agolla \& Ongori, 2009; Hibel et al., 2012; Wilks, 2008).

Seven statistically significant results were observed on the demographics age and enrolment-status that support findings and explanations found in the literature. Since age and enrolment-status are related in the UWI context, we will discuss these two demographics together. At UWI, full-timers are usually between the ages of 17-21. These students generally do not have the types of responsibilities and/or commitments of part-timers (see Davies, 2006; Thawabieh \& Qaisy, 2012). However, young full-timers may cope less effectively since they are still within the transition period of emerging adulthood (Arnett, 2000) and learning to cope with a new environment, more independence, and greater distractions (Rajasekar, 2013; Struthers, et al., 2000). As a result, younger students may experience difficulty in coping with the five mandatory courses required for full-time status, and/or the amount of work in each course. In contrast, older students may be more experienced and organized in handling the amount of academic work but encounter problems with the study/work/family-life balance (Gudrun et al., 2012; Saleh, 2009; Thawabieh \& Qaisy, 2012). Additionally, mature students may experience anxiety (Jones, 2003) related to their return to the classroom (Callender \& Wilkinson, 2012). 
We also observed a statistically significant result between GPA and unpleasant students with a high percentage of students in the FC and Fail GPA groups expressing complaints on this issue. One possible explanation may be due to the fact that the FC students may be worried about the quality/rigor of work and/or contribution from students with lower GPAs to the group endeavour. If FC students view other group members as a hindrance to the group's success, they may complain which can cause other group members to retaliate and increase group conflicts as described by Burns and Sinfield (2008). Alternatively, the Fail GPA group may not be able to contribute anything meaningful to the group endeavour and/or may be delinquent (e.g., late to meetings/late with submissions). Accordingly, this may frustrate other group members who may become unpleasant (see Awino \& Agolla, 2008). However, given our small sample size, our explanations should be cautiously interpreted.

\subsection{Stress Coping Mechanisms}

The five primary coping mechanisms identified by our sample for coping with stress support other researchers, except for sleeping. According to Lemaire and Wallace (2010), quiet time can help to lower stress. Also, FSS students pray for renewed strength thereby joining numerous students globally who employ the same de-stressing strategy (see Fabricatore et al., 2000; Qidwai et al., 2009). Eating more or emotional eating is another common stress reliever and supports Adam and Epel (2007) who studied the positive physiological responses that eating elicits. Similarly, we found that engaging in a hobby is also a stress reliever for our sample to sufficiently recover from the negative effects of the stressor (Ragsdale et al., 2011; Sonnentag et al., 2008). Arguably, a resultant calmer state of mind should allow for a more balanced decision-making-process about the stressor, that is, based more on fact-rather than heightened emotions. An unusual finding in our study was that FSS students slept more as a stress coping strategy. This contradicts the literature which suggests that stress usually results in sleep loss (see Ahrberg et al., 2012; Ginsberg, 2006; Waqas et al., 2015; Van Reeth et al., 2000). Further analysis of our primary coping mechanisms will be discussed under our significant findings which follow.

Eight statistically significant results were observed between the demographic variables (gender, enrolment-status, and age) and the coping strategies used by our sample.

Eat more. According to our data, females ate more perhaps because they experience more social anxiety (Wade et al., 2011) and generally worry more about life, especially working mothers (Byron, 2005). We also found that part-timers tend to eat more than full-timers. One possible explanation may be due to the fact that this group generally has to juggle many different priorities. Consequently, they may require more energy and have to consume more calories. Alternatively, anxiety eating - possibly replaces stress - with pleasure derived from the food (Adam \& Epel, 2007).

Take drugs/smoke. Our finding that a higher percentage of male students use more avoidant coping strategies (Allen \& Holder, 2013; Chen et al., 2009) such as drugs is consistent with the literature (see Bottorff et al., 2009; Cotto, Davis, Dowling, Elcano, Staton, \& Weiss, 2010). Although marijuana use is illegal and carries a social stigma, males are more likely to smoke marijuana perhaps due to the influence of the Rastafarian culture embedded in the Caribbean. In contrast, females are more likely to be socially stigmatized for drug use since it does not fit with the perception of femininity, while men are perceived as more risk takers and rule breakers (Nolen-Hoeksema, 2004).

Engage in a hobby. Our results indicate that more full-timers engage in a hobby. Since full-timers have more free time, a hobby serves as an effective coping strategy for recovery from academics and helps to maintain health. This finding concurs with other research (see Paul et al., 2007; Ragsdale et al., 2011; Sonnentag et al., 2008). Comparatively, more mature part-time students may cut out their recovery activities (Ragsdale et al., 2011; Sonnentag et al., 2008) as they prioritize their commitments.

Party/socialize with friends. We found that full-timers engaged in more social activities (e.g., partying/dancing/socializing) compared to part-timers. Given that full-timers are generally younger students, they would have more free time to party with friends due to fewer responsibilities. This may partially explain why full-time students experience less overall stress than part-timers. Our findings therefore concur with the literature that good social networks are an effective coping mechanism used by students (see MacGeorge et al., 2005; Rajasekar, 2013; Wilks, 2008).

Sleep more. Our unique result indicates that younger students sleep more than older students as a stress relief mechanism. One possible explanation may be that younger students are generally full-timers who do not have any major commitments. Additionally, younger students may be more inclined to drug use which can induce sleep directly (e.g., sleeping pills-Zafar et al., 2008). Alternatively, they may encounter a side effect of their partying (exhaustion) or alcohol induced sleep. They may also use sleep as an avoidance coping strategy. However, more 
research needs to be conducted to determine whether younger students sleeping more is 'natural', drug induced, or as a result of partying too much.

\section{Conclusion}

\subsection{Major Findings}

Our research highlighted that UWI FSS students experience less stress with summer school courses. This finding was fully supported on three demographics — gender, enrolment-status, and age — and partially supported on our GPA demographic.

The key stressors affecting our FSS students were: (i) amount of work in each course, (ii) group projects being a nightmare, (iii) studying and working full-time, (iv) stress associated with work impacting studies, and (v) taking too many courses per semester. Statistically significant results were observed between demographics (enrolment-status and age) and stressors (i), (iii), and (iv). Our research also highlighted that full-time students generally experienced more stress with the volume of work in courses, while part-time students experienced more stress with studying and working full-time and work related issues.

The primary strategies used by FSS students to cope with stress were: (i) taking some quiet time and then resuming studies, (ii) praying for renewed strength, (iii) sleeping more, (iv) eating more, and (v) engaging in a hobby. Statistically significant results were observed between demographics (gender and enrolment-status) and coping mechanism (iv). Our research highlighted that females tended to use comfort mechanisms such as eating more to de-stress while males tended to used more negative coping strategies such as smoking/drugs. We also found that full-timers tended to use more recreational/socialising strategies as stress relievers, and that younger students tended to sleep more which is an unusual finding.

\subsection{Implications for Practice and Policy}

Our findings indicate that our sample of FSS students experienced stress in both semester and summer courses, but that higher stress levels were experienced during the semester. Given that student health and well-being are critical to effective learning, we offer a few suggestions which UWI could consider to help reduce student stress:(1) Extend the 13 week semester or reduce course load of full-time students to 4 courses per semester with an option for 5 courses based on good GPA standing (> 3.00). (2) Include mandatory sessions during orientation for new students to address transition issues such as expectations, study techniques, coping with stress, and support groups.

(3) Provide at least two dedicated counselors to assist students with academic and psychological monitoring.

(4) Provide a small chapel on campus for students who need some quite /meditation/prayer time. (5) Encourage academic staff to make a more coordinated effort to liaise with each other in terms of the number of group projects assigned in the semester, the time frame for submission of assignments, and the manner in which group members are assigned.

\subsection{Limitations of Study and Suggestions for Future Research}

The major limitation associated with our study is the small sample size. Consequently, the researchers acknowledge that findings should be cautiously generalized to the wider FSS student population. In light of this limitation, future research on the topic of student stress should be conducted using a larger sample. Additionally, it would be insightful to conduct this research at the other two campus locations in Jamaica and Trinidad and Tobago to observe if there are differences in stress levels and coping mechanisms among the three campus locations, especially for marijuana use given that Jamaican has a higher Rastafarian population than any of the other campus locations.

\section{Acknowledgements}

We would like to thank Dr. Dwayne Devonish for his invaluable critique of this paper.

\section{References}

Adam, T.C., \& Epel, E.S. (2007). Stress, eating and the reward system. Physiology \& Behavior, 91, 449-458. http://dx.doi.org/10.1016/j.physbeh.2007.04.011

Adshead, L., \& Jamieson, A. (2007). Education and the adult years: A longitudinal perspective on the study pathways of mature students in part-time education. Briefing Paper 3. Birkbeck College, Open University. Retrieved from http://www.bbk.ac.uk/benefits/publications/reports-files/briefingpaper3

Advisory Committee on Student Financial Assistance (2012, February). Pathways to success: Integrating learning with life and work to increase national college completion. A Report to the U.S. Congress and Secretary of 
Education Advisory Committee on Student Financial Assistance. Washington, D.C.. Retrieved from http://www2.ed.gov/about/bdscomm/list/acsfa/ptsreport2.pdf

Agolla, J. E., \& Ongori, H. (2009). An assessment of academic stress among undergraduate students: The case of University of Botswana. Educational Research and Review, 4(2), 63-70. Available online at http://www.academicjournals.org/ERR ISSN 1990-3839

Ahrberg, K., Dresler, M., Niedermaier, S., Steiger, A., \& Genzel, L. (2012). The interaction between sleep quality and academic performance. Journal of Psychiatric Research, 46, 1618-1622. http://dx.doi.org/10.1016/j.jpsychires.2012.09.008

Allen, J., \& Holder, M.D. (2013). Marijuana use and well-being in university students. Journal of Happiness Studies. http://dx.doi.org/10.1007/s10902-013-9423-1

Arnett, J.J. (2000). Emerging adulthood: A theory of development from the late teens through the twenties. American Psychologist, 55(5), 469-480. http://dx.doi.org/10.1037//0003-066X.55.5.469

Austin, A. M., \& Gustafson, L. (2006). Impact of course length on student learning. Journal of Economics and Finance Education, 5(1), 26-37. Retrieved from http://www.santarosa.edu/afa/senate_AustinGustafson.pdf

Awino, J.O., \& Agolla, J.E. (2008). A quest for sustainable quality assurance measurement for universities: Case of study of the University of Botswana. Educational Research Review, 3(6), 213-218. ISSN- 1990-3839

Bandiera, O., Larcinese, V., \& Rasul, I. (2010). Heterogeneous class size effects: New evidence from a panel of university students. Institute for the Study of Labor (p 1-28): Discussion Paper Series-IZA DP No. 4496. http://dx.doi.org/10.1111/j.1468-0297.2010.02364.x

Barbados.Org. (2015). Barbados Churches. Retrieved from http://www.barbados.org/churches

Bland, H. W., Melton, B. F., Welle, P.D., \& Bigham, L. E. (2012). Stress Tolerance: New challenges for the millennial college students. College Student Journal, 46(2), 362-375. ISSN:0146-3934

Borsari, B., \& Carey, K.B. (2006). How the quality of peer relationships influence college alcohol use. Drug Alcohol Review, 25(4), 361-370. http://dx.doi.org/10.1080/09595230600741339

Bottorff, J. L., Johnson, J. L., Moffat, B. M., \& Mulvogue, T. (2009). Relief-oriented use of marijuana by teens. Substance Abuse, Treatment, Prevention, and Policy, 4(7), 1-11. 10. http://dx.doi.org/10.1186/1747-597x-4-7

Britz, J., \& Pappas, E. (2010). Sources and outlets of stress among university students: Correlations between stress and unhealthy habits. Undergraduate Research Journal of the Human Sciences, 9.

Burns, T., \& Sinfield, S. (2008). Essential Study Skills: The Complete Guide to Success at University (2nd ed.). Thousand Oaks, CA: Sage Publication Ltd..

Busari, A.O. (2012). Identifying difference in perceptions of academic stress and reaction to stressors based on gender among first year university students. International Journal of Humanities and Social Science, 2(14), $138-146$.

Byron, K. (2005). A meta-analytic review of work-family conflict and its antecedents. Journal of Vocational Behavior, 67, 169-198. http://dx.doi.org/10.1016/j.jvb.2004.08.009

Callender, C., \& Wilkinson, D. (2012). Futuretrack: Part-time higher education students-the benefits of part-time higher education after three years of study. Retrieved from https://scholar.google.com

Central Intelligence Agency. (2015). Barbados. The World Factbook. Retrieved from https://www.cia.govl

Chen, H., Wong,Y., Ran, M., \& Gilson, C. (2009). Stress among Shanghai university students: The need for social work support. Journal of Social Work, 9(3), 323-344. http://dx.doi.org/10.1177/1468017309334845

Cotto, J.H., Davis, E., Dowling, G.J., Elcano, J.C., Staton, A.B., \& Weiss, S.R. (2010). Gender effects on drug use, abuse, and dependence: An analysis of results from the National Survey on Drug and Health. Gend Med, 7(5), 402-413. http://dx.doi.org/10.1016/j.genm.2010.09.004

Daniel, E. L. (2000). A review of time-shortened courses across disciplines. College Student Journal, 34(2), 298-306. ISSN:0146-3934

Davies, W. M. (2006). Intensive teaching formats: A review. Issues In Educational Research, 16(1), 1-20. Davis, P., \& Brantley, P.J. (2004). Stress, Coping, and Social Support in Health and Behavior. In T.J. Boll, J.M. Raczynski \& L.C. Leviton (Eds.) Handbook of Clinical Health Psychology. Disorders of Behavior and Health. (Vol.2). Washington, DC: American Psychological Association. 
Dawson, D.A., Grant, B.F., Stinson, F.S., \& Chou, P.S. (2005). Psychopathology associated with drinking and alcohol use disorders in the college and general adult populations. Drug and Alcohol Dependence, 77(2), 139150. http://dx.doi.org/10.1016/j.drugalcdep.2004.07.012

Dombeck, M. (2015). A primer on coping and some holiday applications. [Web log post]. Hope happens here. Retrieved from sevencounties.org

Donatelle, R. J. (2012). My health: An outcomes approach. San Francisco: Benjamin Cummings.

Dyson, R., \& Renk, K. (2006). Freshmen adaptation to university life: Depressive symptoms, stress, and coping. Journal of Clinical Psychology, 62(10), 1231-1244. http://dx.doi.org/10.1002/jclp.20295

Eagan, K., Lozano, J. B., Hurtado, S., \& Case, M. H. (2014). The 2014 CIRP Freshmen Survey. Los Angeles: Higher Education Research Institute, UCLA.

Edmonds, E., \& Gonzalez , M. (2010). Caribbean religious history: An introduction. New York: NYU Press. Retrieved June 4, 2015, from Project MUSE database.

Ellison, C. G., Boardman, J. D., Williams, D. R., \& Jackson, J. S. (2001). Religious involvement, stress, and mental health: Findings from the 1995 Detroit area study Social Forces, 80(1), 215-249. ISSN:0037-7732

Fabricatore, A. N., Handal, P. L., \& Fenzel, L.M. (2000). Personal spirituality as a moderator of the relationship between stressors and subjective well-bein. Journal of Psychology and Theology, 28(3), 221-228. ISSN:0091-6471

Ferguson, J. M., \& DeFelice, A. E. (2010). Length of online course and student satisfaction, perceived learning, and academic performance. The International Review of Research in Open and Distributed Learning, 2 (2), 73-84. ISSN:1492-3831

Forsyth, D.R. (2006). Group Dynamics $\left(5^{\text {th }}\right.$ ed). Belmont, CA: Thompson Wadsworth.

Fox, K. (2004). The kleenex for men crying game report: A study of men and crying. The Social Issues Research Centre. Retrieved from www.sirc.org/publik/Crying_Game.pdf

Ginsberg, J.(2006). Academic worry as a predictor of sleep disturbance in college students. Journal of Young Investigators, $18 . \quad$ Retrieved from http://www.jyi.org/issue/academic-worry-as-a-predictor-of-sleep-disturbance-in-college-students/

Gudrun G., Covarrubias Venegas, B., Simbrunner, P., \& Janous, G. (2012). Impact of stress factors on part-time college students. International Journal for Cross-Disciplinary Subjects in Education (IJCDSE), 3(2), $692-698$.

Harrison, D. A., \& Brady, A. R. (2004). Sample size and power calculations using the noncentral t-distribution. The Stata Journal, 2, 142-153.

Health Advocate. (2009). Stress in the workplace: Meeting the challenge. Retrieved from http://www.healthadvocate.com/downloads/webinars/stress-workplace.pdf

Hibel, L. C., Mercado, E., \& Trumbell, J. M. (2012). Parenting stressors and morning cortisol in a sample of working mothers. Journal of Family Psychology, 26(5), 738-746. http://dx.doi.org/10.1037/a0029340

Ho, W. L., \& Polonsky, M. (2012). Marketing students' perception of traditional and intensive delivery: An exploratory study. In ANZMAC 2007: 3Rs, reputation responsibility relevance, 3268-3273. University of Otago, School of Business, Department of Marketing.

Howell, W.C., \& Johnson, L.T. (1982). An evaluation of the compressed course format for instruction in Accounting. The Accounting Review, 57 (2), 403-413.

Jackson, P.B., \& Finney, M. (2002). Negative life events and psychological distress among young adults. Social Psychology Quarterly, 65(2), 186-201. ISSN:0190-2725. http://dx.doi.org/10.2307/3090100

Johnson, M. (2009). Community College Students' Perception of Stress. Journal of Biology of Exercise, 5(1), 15-28. http://dx.doi.org/10.4127/jbe.2009.0022

Johnsson, K.O., \& Berglund, M. (2006). Comparison between a cognitive behavioural alcohol programme and postmailed minimal interventions in high-risk drinking university freshmen: Results from a randomized controlled trail. Alcohol and Alcoholism, 41(2), 174-180. http://dx.doi.org/10.1093/alcalc/agh243

Jones, C. (2003). Apprehension and achievement - twinpoles of the adult learning experience. (GWERIN Occasional Paper No. 4). Centre for Community and Lifelong Learning at University of Wales College Newport.

Kelly, W.E., Kelly, K.E., \& Clanton, R.C. (2001). The relationship between sleep length and grade-point-average among college students. College Student Journal, 35(1), 84-86. ISSN:0146-3934 
Klinic Community Health Centre (2010). Stress \& stress management. Retrieved at http://hydesmith.com/de-stress/files/StressMgt.pdf

Lemaire, J.B. \& Wallace, J.E. (2010). Not all coping strategies are created equal: A mixed methods study exploring physicians' self reported coping strategies. BMC Health Services Research, 10, 1-10. http://dx.doi.org/10.1186/1472-6963-10-208

Lavrakas, P. J. (2008). Self-administered questionnaire. In Encyclopedia of Survey Research Methods. Sage Publications, Inc. http://dx.doi.org/10.4135/9781412963947

Linn, B.S. \& Zeppa, R. (1984). Stress in junior medical students: Relationship to personality and performance. Journal of Medical Education, 59, 7-12. http://dx.doi.org/10.1097/00001888-198401000-00002

Ludovici, J. (2012, October 27). Student stress and college failure [Web log post]. Retrieved from studentstrategy101.com/blog/2012/10/27/student-stress-and-college-failure/ $\wedge$

MacGeorge, E. L., Samter, W., \& Gillihan, S. J. (2005). Academic stress, supportive communication, and health. Communication Education, 54, 365-372. ISSN-0363-4523. http://dx.doi.org/10.1080/03634520500442236

Masih, P. P. \& Gulrez, N. K. (2006). Age and Gender Differences on Stress. In A. Husain, \& M. I. Khan (Eds.). Recent Trends in Human Stress Management, 97-104. New Delhi, India: Global Mission Publishing House.

McKenzie, K., \& Schweitzer, R. (2001). Who succeeds at university? Factors predicting academic performance in first year Australian university students. Higher Education Research and Development, 20, 21-33. http://dx.doi.org/10.1080/07924360120043621

Misra, R., \& Castillo, L. G. (2004). Academic Stress among college students: Comparison of American and international students. International Journal of Stress Management, 11(2), 132-148. http://dx.doi.org/10.1037/1072-5245.11.2.132

Nasiri E., \& Shokrpour N. (2012). Comparison of intensive and non-intensive English courses and their effects on the student's performance in an EFL university context. European Scientific Journal, 8(8), 127-137. e - ISSN 18577431

National Institute of Mental Health. (2003). Depression and college students (NIH Publication No. 97-4266). Washington, DC: U.S.

Nolen-Hoeksema, S. (2004). Gender differences in risk factors and consequences for alcohol use and problems. Clinical Psychology Review, 24, 981-1010. http://dx.doi.org/10.1016/j.cpr.2004.08.003

Pallant, J. (2003). SPSS survival manual: A step by step guide to data analysis using SPSS. Philadelphia, PA: Open University Press.

Paul, G., Elam, B., \& Verhulst, S.J. (2007). A longitudinal study of students' perceptions of using deep breathing meditation to reduce testing stresses. Teaching and Learning in Medicine, 19(3), 287-292. http://dx.doi.org/10.1080/10401330701366754

Picchioni, D., Reith, R., Nadel, J., \& Smith, C. (2014). Sleep, plasticity and the pathophysiology of neurodevelopmental disorders: The potential roles of protein synthesis and other cellular processes. Brain Sciences, 4(1), 150-201. http://dx.doi.org/10.3390/brainsci4010150

Qidwai, W., Tabassum, R., Hanif, R., \& Khan, F.H.(2009). Belief in prayers and its role in healing among family practice patients visiting a teaching hospital in Karachi, Pakistan. Pakistan Journal of Medical Science, 25(2), 182-189. http://dx.doi.org/10.5001/omj.2010.30

Ragsdale, J.M., Beehr, T.A., Grebner, S., \& Han, K. (2011). An integrated model of weekday stress and weekend recovery of students. International Journal of Stress Management, $18 \quad$ (2), $153-180$. http://dx.doi.org/10.1037/a0023190

Rajasekar, D. (2013). Impact of academic stress among the Management students of AMET University-An analysis. AMET Journal of Management, 32-39. ISSN: 2231-6779

Reardon, J., Payan, J., Miller, C., \& Alexander, J. (2008). Optimal class length in marketing undergraduate classes: An examination of preference, instructor evaluations, and students' performance. Journal of Marketing Education, 30(1), 12-20. http://dx.doi.org/10.1177/0273475307312193

Sadeh, A., \& Gruber, R. (2002). Stress and sleep in adolescence: A clinical-developmental perspective. In M. A. Carskadon (Ed.). Adolescent sleep patterns: Biological, social, and psychological influences, 236-253. New York: Cambridge University Press. 
Saleh, K,L. (2009). Managing to manage workplace stress. The Psychology Foundation of Canada. Retrieved from http://www.psychologyfoundation.org/pdf/publications/managing_to_manage.pdfto ManageStress

Schneiderman, N., Ironson, G., \& Siegel, S. D. (2005). Stress and health: Psychological, behavioral, and biological determinants. Annual Review of Clinical Psychology, 1, 607-6. http://dx.doi.org/10.1146/annurev.clinpsy.1.102803.144141

Scott, P. A. (2003). Attributes of high-quality intensive courses. New Directions for Adult and Continuing Education, 97, 29-38. ISSN: 1052-2891. http://dx.doi.org/10.1002/ace.86

Selye, H. (1980). A personal message from Hans Selye. Journal of Extension, May/June: 1-11.

Sonnentag, S., Binnewies, C., \& Mojza, E. J. (2008). "Did you have a nice evening?” A day-level study on recovery experiences, sleep, and affect. Journal of Applied Psychology, 93, 674-684. http://dx.doi.org/10.1037/0021-9010.93.3.674

Spurling, S. (2001). Compression of semesters or intensity of study: What is it that increases student success? ERIC Document Reproduction Service, No. ED467474.

Struthers, C.W., Perry, R.P., \& Menec, V.H. (2000). An examination of the relationships among academic stress, coping motivation and performance in college. Research in Higher Education. 41, 581-592. http://dx.doi.org/10.1023/A:1007094931292

Sulaiman, T., Hassan, A., Sapian, V. M., \& Abdullah, S. K. (2009). The level of stress among students in urban and rural secondary schools in Malaysia. European Journal of Social Sciences, 10(2), 179-184.

Thawabieh, A. M., \& Qaisy, L.M. (2012). Assessing stress among university students. American International Journal of Contemporary Research, 2(2), 110-116.

The American College Health Association (2008). National college health assessment Spring 2007 reference group data report (abridged). Journal of American College Health, 56 (5), 469-479. http://dx.doi.org/10.3200/JACH.56.5.469-480

The University of the West Indies (2011). Statistical review academic year 2009/2010. Retrieved from www.mona.uwi.edu/.../statistics/2009-2010/

Trockel, M.T., Barnes, M.D., \& Egget, D.L. (2000). Health-related variables and academic performance among first-year college students: Implications for sleep and other behaviors. Journal of American College Health, 49, 125-132. ISSN: 0744-8481. http://dx.doi.org/10.1080/07448480009596294

Van Reeth, O., Weibel, L., Spiegel, K., Leproult, R., Dugovic, C., \& Maccari, S. (2000). Interactions between stress and sleep: From basic research to clinical situations. Sleep Medicine Reviews, 4, 201-219. http://dx.doi.org/10.1053/smrv.1999.0097

Wade, C., Jacobsen, B.S., \& Forste, R. (2011). The Wired Generation: Academic and Social Outcomes of Electronic Media Use Among University Students. Cyberpsychology, Behavior, and Social Networking, 14 (5), 275-280. http://dx.doi.org/10.1089/cyber.2010.0135

Waqas, A., Khan, S., Sharif, W., Khalid, U., \& Ali, A. ( 2015). Association of academic stress with sleeping difficulties in medical students of a Pakistani medical school: A cross sectional survey. Peer Journal, 1-11. http://dx.doi.org/10.7717/peerj.840

Weyandt, L. L., Janusis, G., Wilson, K. G., Verdi, G., et al. (2009). Nonmedical prescription stimulant use among a sample of college students: Relationship with psychological variables. Journal of Attention Disorders, 13(3), 284-296. http://dx.doi.org/10.1177/1087054709342212

White, A. A. K. (2009). From comfort zone to performance management. Belgium : White \& MacLean Publishing.

Wilks, S. E. (2008). Resilience amid academic stress: The moderating impact of social support among Social Work students. Advances in Social Work, 9(2), 106-125.

Yang, H.J. (2004). Factors affecting student burnout and academic achievement in multiple enrolment programs in Taiwan's technical-vocational colleges. Internationa Journal of Educational Development, 24, 283 -301. http://dx.doi.org/10.1016/j.ijedudev.2003.12.001

Zafar, S.N., Syed, R., Waqar, S., Zubairi, A.J., Vaqar, T., Shaikh, M., Yousaf, W., Shahid, S., \& Saleem, S. (2008). Self-medication amongst university students of Karachi: prevalence, knowledge and attitudes. Journal of Pakistan Medical Association, 58(4), 214-217. 